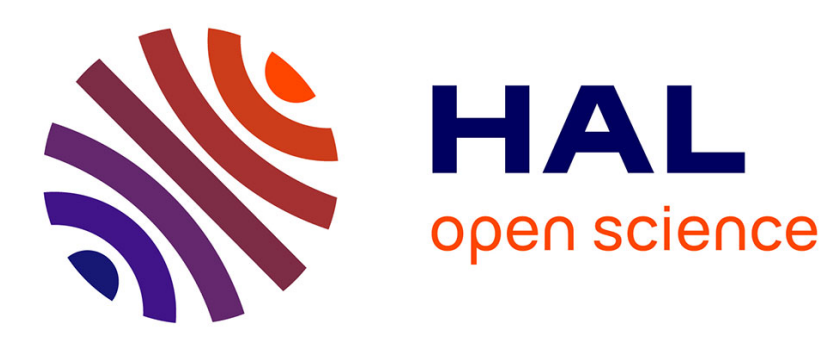

\title{
Collusion through price ceilings? In search of a focal-point effect
}

\author{
Dirk Engelmann, Wieland Müllerz
}

\section{To cite this version:}

Dirk Engelmann, Wieland Müllerz. Collusion through price ceilings? In search of a focal-point effect. Journal of Economic Behavior and Organization, 2011, 79 (3), pp.291. 10.1016/j.jebo.2011.02.008 . peer-01053435

\section{HAL Id: peer-01053435 https://hal.science/peer-01053435}

Submitted on 31 Jul 2014

HAL is a multi-disciplinary open access archive for the deposit and dissemination of scientific research documents, whether they are published or not. The documents may come from teaching and research institutions in France or abroad, or from public or private research centers.
L'archive ouverte pluridisciplinaire HAL, est destinée au dépôt et à la diffusion de documents scientifiques de niveau recherche, publiés ou non, émanant des établissements d'enseignement et de recherche français ou étrangers, des laboratoires publics ou privés. 


\section{Accepted Manuscript}

Title: Collusion through price ceilings? In search of a focal-point effect

Authors: Dirk Engelmann, Wieland Müllerz

PII: $\quad$ S0167-2681(11)00072-2

DOI: $\quad$ doi:10.1016/j.jebo.2011.02.008

Reference: $\quad$ JEBO 2710

To appear in: Journal of Economic Behavior \& Organization

Received date: $\quad 10-5-2010$

Revised date: 28-1-2011

Accepted date: $\quad$ 4-2-2011

Please cite this article as: Engelmann, D., Müllerz, W., Collusion through price ceilings? In search of a focal-point effect, Journal of Economic Behavior and Organization (2008), doi:10.1016/j.jebo.2011.02.008

This is a PDF file of an unedited manuscript that has been accepted for publication. As a service to our customers we are providing this early version of the manuscript. The manuscript will undergo copyediting, typesetting, and review of the resulting proof before it is published in its final form. Please note that during the production process errors may be discovered which could affect the content, and all legal disclaimers that apply to the journal pertain. 


\title{
Collusion through price ceilings? In search of a focal-point effect*
}

\author{
Dirk Engelmann ${ }^{\dagger}$ \\ University of Mannheim
}

\author{
Wieland Müller $\ddagger$ \\ University of Vienna, \\ CentER, TILEC, Tilburg University
}

January 27, 2011

\begin{abstract}
We resume the search for a collusive focal-point effect of price ceilings in laboratory markets. We argue that market conditions in previous studies were unfavorable for collusion which may have been responsible for not finding such a focal-point effect. Our design aims at maximizing the likelihood of a focal-point effect. Nevertheless, our results again fail to support the focalpoint hypothesis. Collusion is as unlikely in markets with a price ceiling as in markets with unconstrained pricing. Overall, static Nash equilibrium predicts the data fairly accurately. We argue this might warrant re-interpretation of field studies on anti-competitive effects of price ceilings.
\end{abstract}

JEL Classification numbers: L13, L41, C92.

Keywords: Collusion, competition policy, experimental economics, focal point.

\footnotetext{
${ }^{*}$ We are grateful to Maria Bigoni, Hans Normann, Charles Plott, Sigrid Suetens, the editor J. Barkley Rosser, Jr., and two anonymous referees as well as seminar participants at DIW Berlin, the University of Erlangen-Nuremberg and the University of Padua for helpful comments. Dirk Engelmann acknowledges financial support from the institutional research grant AV0Z70850503 of the Economics Institute of the Academy of Sciences of the Czech Republic, v.v.i. Wieland Müller acknowledges financial help from the Netherlands Organisation for Scientific Research (NWO) through a VIDI grant.

${ }^{\dagger}$ Department of Economics, University of Mannheim, L7, 3-5, 68131 Mannheim, E-mail: dirk.engelmann@unimannheim.de, Web: http://engelmann.vwl.uni-mannheim.de/. Dirk Engelmann is also an Affiliate of the Centre for Experimental Economics at the University of Copenhagen, a CESifo Research Network Fellow and a Senior Researcher at the Economics Institute of the Academy of Sciences of the Czech Republic, v.v.i.

${ }^{\ddagger}$ Department of Economics, University of Vienna, Brünnerstrasse 72, 1210 Vienna, Austria, Email: wieland.mueller@univie.ac.at, Web: http://homepage.univie.ac.at/wieland.mueller/.
} 
January 28, 2011

Dear Professor Neilson,

We are grateful for the reports we received on our paper

"Collusion through price ceilings? In search of a focal-point effect"

(JEBO-D-10-00245) by Dirk Engelmann and myself and the invitation to revise and resubmit it. We apologize for the long delay in resubmitting the paper. This delay was due to the fact that both Dirk Engelmann and myself have new affiliations and moved to new places.

The revision addresses all the issues raised by the editor and the referees. In what follows we describe in detail how we responded to the editor's and the referees' comments.

Sincerely,

Wieland Müller 


\section{In response to the editor's comments, we did the following:}

- We have shortened the paper to 25 pages, mainly by briefly summarizing our analysis of the number of colluding pairs that we presented on pages 14-17 in the original version of the paper. The table and detailed discussion have been moved to Appendix B in the supplementary content to be published online.

- We moved the proof of Proposition 1 to Appendix A in the document "Supplementary Content."

- We have changed the style of the references into proper JEBO format.

In response to the comments of referee \#1, we did the following:

- We provide the instructions of our experiments in Appendix $\mathrm{C}$ in the document "Supplementary Content" to be made available on JEBO's homepage.

- We have corrected the typos.

In response to the comments of referee $\# 2$, we did the following:

- As mentioned above, we have shortened the paper.

- We follow the referee's suggestion of explicitly acknowledging the use of undergraduate university students in the implementation subsection where we add that our subjects where (largely undergraduate) students from a wide variety of subjects.

- We also discuss in the introduction in more detail possible reasons why our study using student subjects may not be easily generalizable. However, we actually do believe that most arguments why firms would behave differently than our subjects make it rather less than more likely that they would use price ceilings as collusive focal points. How convincing our arguments are should in our mind be ultimately be left to the eventual readers.

- We also added the following footnote (footnote 19) in the conclusions where we discuss possible routes for future research:

"Among possible alternatives for further research are to check the effect of allowing sellers to communicate, having groups instead of individuals act in the role of sellers and of using experienced subjects." 


\title{
Collusion through price ceilings? In search of a focal-point effect
}

\author{
January 27, 2011
}

\begin{abstract}
We resume the search for a collusive focal-point effect of price ceilings in laboratory markets. We argue that market conditions in previous studies were unfavorable for collusion which may have been responsible for not finding such a focal-point effect. Our design aims at maximizing the likelihood of a focal-point effect. Nevertheless, our results again fail to support the focalpoint hypothesis. Collusion is as unlikely in markets with a price ceiling as in markets with unconstrained pricing. Overall, static Nash equilibrium predicts the data fairly accurately. We argue this might warrant re-interpretation of field studies on anti-competitive effects of price ceilings.
\end{abstract}

JEL Classification numbers: L13, L41, C92.

Keywords: Collusion, competition policy, experimental economics, focal point. 


\section{Introduction}

The theory of competitive markets predicts that the effect of a price ceiling on the level of prices is either negative (in case the ceiling is binding) or zero (in case the ceiling is at or above the competitive price). Industrial economists such as Scherer and Ross (1990), however, have argued that price ceilings can weaken competition as they may serve as collusive focal points for pricing decisions (Schelling, 1960). To see this, note that the Folk Theorem (see for example Tirole, 1988) predicts that infinitely many prices can occur as outcomes of collusive equilibria in infinitely repeated games if the discount factor is sufficiently high. This suggests a coordination problem when firms attempt to collude. Here, a price ceiling may function as a focal point on which firms coordinate. Thus, price ceilings could facilitate tacit collusion and lead to higher prices.

Indeed, there is mounting evidence for a collusive focal-point effect of price ceilings in various markets. Sheahan (1961), studying the effect of price controls in postwar France, reports that "the establishment of official ceilings provides a focus for individual quotations which might otherwise have differed" (p.532). Knittel and Stango (2003) investigate the interest rates of U.S. credit cards in the 1980s where various price ceilings were effective and report that "tacit collusion at nonbinding state-level ceilings was prevalent during the early 1980's." Eriksson (2004, p.1), analyzing the 1999 deregulation of the market for dental services in Sweden, states that the "Swedish government was worried that the ceiling was serving as a focal point for implicit price collusion" and that "a removal of the price ceiling could lead to increased competition and lower prices." DeYoung and Phillips (2006, p.1) document that "over time, payday loan prices in Colorado have gravitated toward the legislated price ceiling." Finally, Ma (2007) studies price ceilings in Taiwan's flour market, and finds evidence that firms in this market set prices "above competitive equilibrium levels during most of the regulation period" and that "[o]bservations on prices also show that all flour firms set their prices equal to ceilings, without exception."

In contrast to this field evidence, laboratory experiments have so far failed to find a collusive focal-point effect of price ceilings. In this paper, we report on a new experiment. We believe that such further research is called for, because earlier studies have made such collusive effects rather difficult. The first studies, Isaac and Plott (1981) and Smith and Williams (1981) find that price ceilings actually lower prices in double auctions. With the benefit of hindsight, this is perhaps not surprising as by now double auction markets are known to reliably converge to the competitive equilibrium, making it very unlikely for any collusive effects of price ceilings to occur. Coursey and 
Smith (1983) arguably constitute a stronger case against the focal-point hypothesis, as they find convergence to the competitive equilibrium and thus no collusive effects of price ceilings in postedoffer markets, which are generally more vulnerable to collusion than double auctions. However, in the design of Coursey and Smith (1983) the incentives to collude are very small, because even for the highest price ceiling they study, the total collusive profit would be less than $10 \%$ above the equilibrium profit (and some firms might even be worse off). Furthermore, Nash-equilibria (of the game between the four sellers with buyers assumed to maximize payoffs) are in mixed strategies with positive probability on prices above the competitive equilibrium, such that it is possible that the price ceiling is binding with respect to the Nash-equilibrium prices. ${ }^{1}$ Finally, the evidence against the focal-point hypothesis reported in Engelmann and Normann (2009), who study posted offer markets with four symmetric sellers but larger incentives for collusion at the price ceiling than in Coursey and Smith (1983) appears to just confirm that collusion with four firms in an experimental market is hard to achieve (see, e.g., Huck, Normann, and Oechssler, 2004).

The design of the experiments reported in this paper has several features that we expected to be conducive to collusive pricing (at the ceiling). First, we have fixed pairs of players interacting repeatedly. This has been shown to lead to higher collusion rates in laboratory markets (see, e.g., Huck, Normann, and Oechssler, 2004). Second, to prevent markets from being highly collusive already in the absence of a price ceiling, we chose asymmetric cost schedules for the sellers such that they disagree about the optimal collusive price. Imposing a price ceiling could potentially resolve this problem by making collusion at the price ceiling the preferred outcome for both firms. Third, the unique Nash equilibrium is the upper end of the competitive price range. Fourth, collusion at the price ceiling, instead of choosing the Nash-equilibrium price, would increase profits by up to $31 \%$. Hence, our design provides substantial incentives to collude at the price ceiling and we therefore believe it is better suited to test the hypothesis that price ceilings facilitate tacit collusion. As in previous designs, there are many prices at which firms could collude. This coordination problem might be resolved with a price ceiling since it presents a focal point for coordination.

We note that our design was not chosen with the aim of providing a realistic model of any one specific market but with the aim of designing a market most conducive to an experimental

\footnotetext{
${ }^{1}$ Due to a lack of detail reported in Coursey and Smith (1983) it is impossible to calculate the Nash equilibrium. For standard distributions of cost schedules (such that no seller sells more than two units in the competitive equilibrium), however, it is evident that there is no pure-strategy Nash equilibrium. Mixed-strategy equilibria in turn have to put positive probability on prices above the competitive price range.
} 
existence proof of a collusive focal-point effect of price ceilings. We aim at achieving this by making collusion not generally easy or difficult, but by trying to maximize the ease of collusion with a ceiling compared to without.

We also note that the issue of generalizability of results from experiments where student subjects take the role of firms, is arguably less of a concern in the present experiment than for typical market experiments. ${ }^{2}$ The hypothesis we are testing, namely whether a price ceiling can serve as a focal point to solve a coordination problem is a psychological explanation that is not specific to certain markets and there is a-priori no reason why it should work better or worse for experienced managers than for students. Testing this psychological hypothesis in the laboratory would thus allow us to infer its plausibility in non-experimental markets. Nevertheless, our use of a standard student subject pool may miss some important issues that matter for collusion of firms in the field. For example, our participants lack experience in decision making in such settings. However, if decision makers are more experienced, we would rather expect them to find more sophisticated ways to coordinate than relying on focal points. Thus the role of a price ceiling as a focal point would appear to be rather more important in the laboratory than outside. Decision making in the field is also largely driven by committees while we have individuals making decisions. Again, our expectation is that committees are rather able to follow more sophisticated strategies and rely less on focal points. Furthermore, we exclude communication. Communication makes collusion easier, but again this implies that firms would have to rely even less on price ceilings.

Despite choosing a design conducive to inducing price ceilings to have a collusive effect, we neither find evidence of a focal point in the sense of clustering of prices at the ceiling (prices at the ceiling are more likely to result from censoring) nor an increase in the number of collusive markets in the presence of a price ceiling, nor of average prices. To the contrary, price ceilings even induced lower average prices, typically in the early periods after their imposition. As a next step, in further treatments we removed information about the demand curve. This should make it more likely to induce the hypothesized collusive focal-point effect. That is, by removing common knowledge on kinks in the demand curve that could serve as alternative focal points, we give the hypothesis that price ceilings could lead to more collusion an even better shot. Hence, we conducted an additional

\footnotetext{
${ }^{2}$ One key reason why the results from market experiments may not generalize to actual product markets is that other-regarding preferences may be more important in the laboratory than in markets. Other-regarding preferences might matter in our experiment, but the issue here is one of collusion, which is mutually beneficial both in the laboratory and the market.
} 
series of markets in which we kept features of the first treatment, but gave sellers no information about the precise shape of the demand curve. More precisely, sellers were only informed that there is an unspecified number of simulated buyers who each have a certain (maximum) willingness to pay for a unit of the good without specifying what the buyers' maximal willingness to pay was. The markets with this minimal information design showed even less clustering at the ceiling and fewer colluding pairs and again a decrease of average prices when a price ceiling was in place. We also find no increase in a profit-based measure of collusiveness thanks to a price ceiling.

Our observations, together with previous experimental results, suggests that a simple focalpoint effect might not be sufficient for inducing collusion and hence that other aspects might also matter in the field. Specifically, we discuss below that a price ceiling might also be interpreted as a signal of impunity for prices up to that level, which reduces the (perceived as well as possibly actual) risk of collusion. In the laboratory, where collusion is not illegal and not punished, such a signal would be irrelevant. Hence this hypothesis can better explain than the focal-point hypothesis why price ceilings appear to have anti-competitive effects in the field, but not in the laboratory.

We describe the details of our experimental markets, the theoretical predictions, and the implementation in Section 2. In Section 3 we present the results. Finally, we briefly summarize and discuss our results and their implications in Section 4.

\section{Experimental Design}

\subsection{The Experimental Market}

Our experimental markets were designed to facilitate collusion at a price ceiling, while making collusion in the absence of a price ceiling relatively difficult. First, since double-auctions very robustly converge to the competitive equilibrium, we chose a posted-offer market design. Second, we are not interested in buyer behavior and buyers might resist high collusive prices, so we chose to simulate buyers. This also allowed us to implement a simple rule of how demand is split if the sellers set equal prices. ${ }^{3}$ Moreover, using simulated buyers facilitates collusion as sellers with other-regarding preferences might refrain from colluding if buyers become substantially worse off. ${ }^{4}$

\footnotetext{
${ }^{3}$ The absence of this rule notoriously complicates the calculation of Nash-equilibria in posted-offer markets. See e.g. Borck et al. (2002) and below for a discussion.

${ }^{4}$ Other obvious advantages are that simulating buyers economizes on the number of experimental sessions and their costs as well as reduces noise due to potentially erratic buyer behavior. The most obvious disadvantage is that
} 


\begin{tabular}{ccccccc}
\hline \hline Unit & 1 & 2 & 3 & 4 & 5 & 6 \\
\hline$M C$ for Seller 1 & 1 & 14 & 14 & 23 & 31 & 31 \\
$M C$ for Seller 2 & 7 & 7 & 17 & 22 & 32 & 32 \\
\hline \hline
\end{tabular}

Table 1: Marginal costs for the sellers in the experimental market.

\begin{tabular}{lcccc}
\hline \hline Willingness to pay & 48 & 29 & 21 & 13 \\
\hline Number of buyers & 2 & 2 & 2 & 2 \\
\hline \hline
\end{tabular}

Table 2: Willingness to pay for the eight (simulated) buyers in the experimental market.

A posted-offer market with simulated buyers is effectively just a Bertrand-game. We framed the experiments, however, like a posted-offer market, i.e. giving an explicit rule how the (simulated) buyers would shop after sellers set their prices. This was done to facilitate understanding of the market mechanism and also to make our study closely comparable to previous studies.

In our markets, the same two sellers interact repeatedly. This is obviously the most likely scenario in order to generate collusion. ${ }^{5}$ To prevent markets from being highly collusive already in the absence of a price ceiling, we chose asymmetric cost schedules for the sellers such that they disagree about the optimal collusive price. Specifically, each seller could produce up to six units and marginal costs are as in Table 1. Costs are only incurred for units actually sold. In each market there were eight buyers who could buy one unit each. Their willingness to pay is given in Table 2 . The demand and supply curves are shown in Figure 1. Sellers post their prices simultaneously and only once in every period. Price offers were restricted to integers. Our design differs from standard posted-offer markets in various aspects. Sellers are automatically committed to sell (given sufficient demand) the maximal quantity such that marginal costs do not exceed the price. Simulated buyers are rationed efficiently, that is they buy in order of decreasing willingness to pay and from sellers in

we remove the design further from the field. As argued above, however, the purpose of our study is to attempt to generate an existence proof for a focal-point effect of price ceilings in the laboratory and not to mimic any field market as closely as possible.

${ }^{5}$ We note that with finite repetition collusion is theoretically less likely than in an infinitely repeated game. An infinitely repeated game cannot be implemented in the laboratory. Nevertheless, experimental evidence suggests that subjects do only few steps of backward induction. For example, Normann and Wallace (2006), comparing finitely repeated games with indefinitely repeated games (i.e. games where the exact number of repetitions is unknown to the subjects) find little difference in overall cooperation rates in Prisoner's Dilemma games and end-game effects confined to the last few periods. 


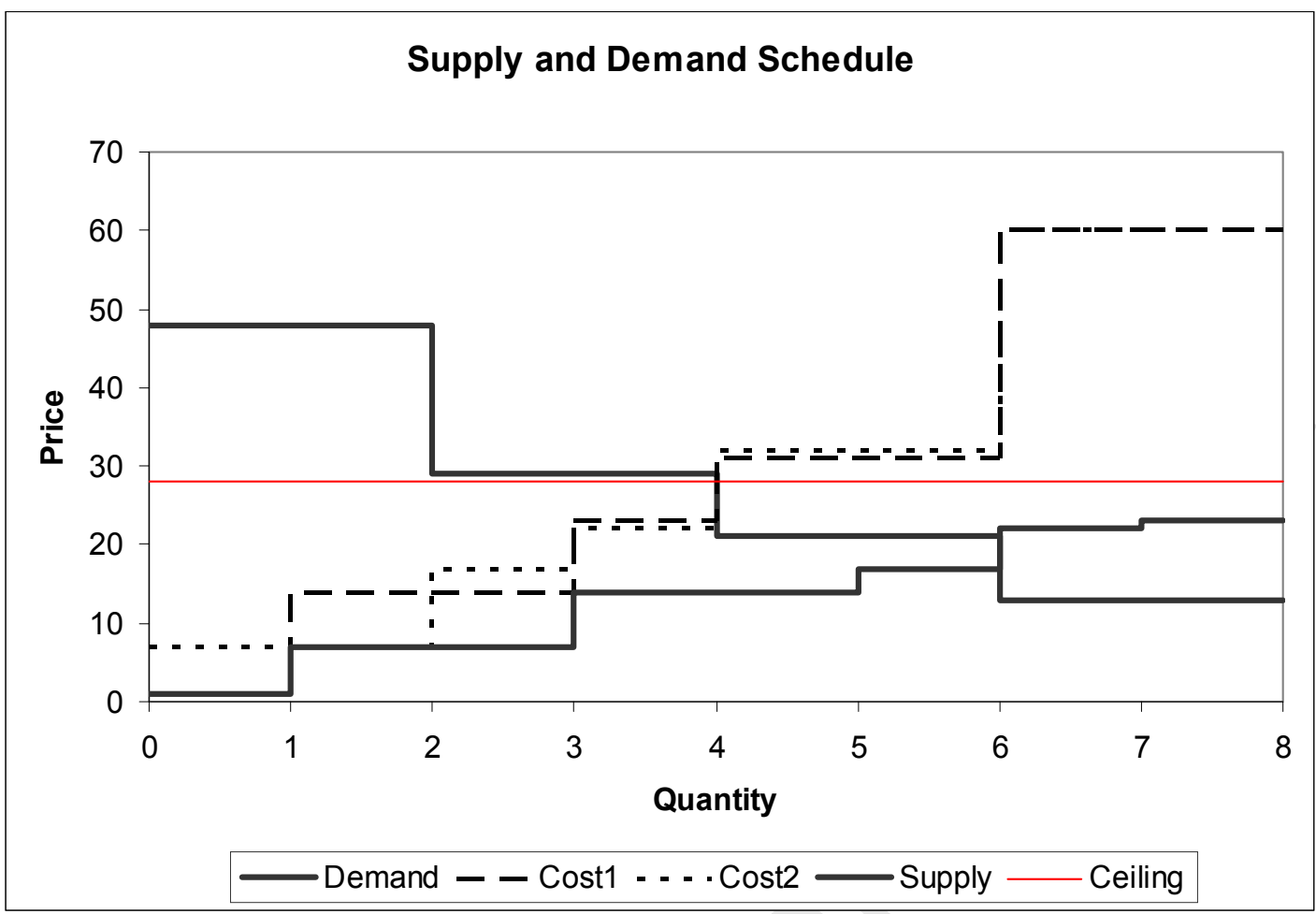

Figure 1: Supply and demand in the experimental market.

Note: The supply curve and demand curve overlap for prices between 17 and 21, which gives us thus a competitive price range of $[17,21]$, with the upper end equal to the unique Nash-equilibrium price.

order of increasing price. If several sellers charge equal prices, buyers split their demand equally. ${ }^{6}$ Given the cost and demand schedules, an individual seller could actually never sell more than four units and sellers could in total not sell more than six units. Additional buyers and units were added in order to prevent sellers to focus immediately on the range of prices close to the Nash equilibrium or the collusive outcome.

\footnotetext{
${ }^{6}$ Posted-offer markets are often plagued by a multiplicity of Nash equilibria. Moreover, these are often derived assuming that buyers split their demand equally between sellers with identical prices (see, e.g. Davis and Holt, 1993), which even rational human buyers have no reason to do (and the experimental software would usually not even allow them to do). Abolishing this assumption in general destroys all pure-strategy Nash equilibria. Implementing the above rule we elimate this problem which simplifies the calculation of expected profits, eliminates any randomness and, for our specific cost and demand schedules, allows us to determine a unique pure-strategy Nash equilibrium. Sellers were also informed that units sold were not restricted to integers. While selling half-units can actually not happen for the given cost and demand schedules, sellers in the treatment without information about the buyers' willingness to pay could not infer this.
} 


\begin{tabular}{lcccc}
\hline \hline & Nash Price & Nash Profit & Cartel Price & Cartel Profit \\
\hline Seller 1 & 21 & 34 & 48 & 47 \\
Seller 2 & 21 & 32 & 48 & 41 \\
\hline \hline
\end{tabular}

Table 3: Profits for both sellers in Nash equilibrium (which is also the upper end of the competitive price range) and in the joint-profit maximizing cartel.

\subsection{Equilibrium Predictions}

Inspecting Figure 1, it is easy to see that the competitive price range is $[17,21]$ with market demand and supply both equal to six units. Each seller sells three units and at the upper end of the competitive price range (which is also the unique Nash equilibrium, see below), profits are $\pi_{1}=3 \times 21-(1+14+14)=34$ and $\pi_{2}=3 \times 21-(7+7+17)=32$.

Obviously, the only candidates for joint-payoff maximizing prices are at the kinks of the demand curve, i.e. $P=29$ and $P=48$, because any intermediate price will lead to the same demand as at the next kink. Joint profits are maximized at $P_{1}=P_{2}=48$. Each seller then sells one unit and $\pi_{1}=48-1=47$ (38\% more than in the Nash equilibrium), $\pi_{2}=48-7=41$ (28\% more than in Nash equilibrium). Seller 2, however, would prefer to collude at $P_{1}=P_{2}=29$. Then each seller sells two units and $\pi_{1}=58-15=43$ (27\% more than in the Nash equilibrium), $\pi_{2}=58-14=44(38 \%$ more than in the Nash equilibrium). Note that we intentionally designed the markets such that the sellers do not agree on their preferred collusive outcome, in order to hinder collusion without a price ceiling and thus maximize the possible impact of the price ceiling on collusion. We summarize the Nash and cartel prices and profits in Table 3. The unique Nash equilibrium is derived in the following proposition. ${ }^{7}$

Proposition 1 The unique Nash equilibrium is both sellers setting $P_{1}=P_{2}=21$. In this equilibrium, each seller sells three units and profits are $\pi_{1}=34, \pi_{2}=32$.

The proof can be found in Appendix A in the supplementary content and proceeds in the usual way, first showing that $P_{1}=P_{2}=21$ is a Nash equilibrium and then demonstrating that there is no other Nash equilibrium in pure or mixed strategies.

\footnotetext{
${ }^{7}$ We note that we are calculating the Nash equilibrium as if sellers knew the cost function of the other firm. While this is not legitimate early on in the game, they can reasonably quickly learn their demand curves. Thus for experienced players the Nash equilibrium is a plausible benchmark. The same is true, albeit with more to be learned, for the markets where sellers do not know the demand function.
} 


\begin{tabular}{ccc}
\hline \hline & Ceiling in Periods 1-30 & Ceiling in Periods 31-60 \\
\hline Information & YesNo-Info & NoYes-Info \\
No Information & YesNo-NoInfo & NoYes-NoInfo \\
\hline \hline
\end{tabular}

Table 4: Overview of the experimental treatments.

\subsection{Implementation}

Two sellers interacted in the same market for 60 periods. A price ceiling was in place either in the first 30 periods (Treatment "YesNo") or in the last 30 periods (Treatment "NoYes"). Sellers were informed at the beginning of the experiment that a change in market conditions would occur after 30 periods without pointing out that this would relate to the introduction or the abolishment of a price ceiling. Written instructions were identical in both treatments and did not make a reference to price ceilings (the instructions can be found in Appendix $\mathrm{C}$ in the supplementary content). Treatment YesNo then started with a computer screen that informed participants that as an additional rule to what was stated in the written instructions a price ceiling would be in place. The price ceiling was always $C=28$. We choose this price ceiling, because at this price joint profits are maximized subject to the constraint of the ceiling being below the kink in the demand curve at 29. Obviously, the ceiling needed to be different than either of the kinks to distinguish collusion at the ceiling from collusion at a kink. Given that, any ceiling larger than 29 would yield lower joint profits than collusion at 29, which would have lead to two competing candidates for collusive prices and hence made an effect of the price ceiling less likely. Note that by pricing at the ceiling, instead of the Nash-equilibrium price of 21 , Seller 1 and Seller 2 would increase profits by about $21 \%$ and $31 \%$, respectively.

Treatments furthermore differed by the information sellers had about the buyers. In the first two treatments (YesNo-Info and NoYes-Info), sellers were informed about the buyers' willingness to pay. In the second two treatments (YesNo-NoInfo and NoYes-NoInfo) they were only informed that each buyer had a given willingness to pay (they were also not informed about the number of buyers). This yields a $2 \times 2$ design as given in Table 4 . Without demand information, colluding in the absence of a price ceiling is particularly (and intentionally) difficult. This increases the scope for the price ceiling to make collusion more likely, as it provides a unique focal point.

In each of the Info treatments we had 17 pairs of sellers and in each of the NoInfo treatments we had 18 pairs. Hence our total number of subjects was 140, yielding a total of 8400 price 
choices. The Info treatments were run at Royal Holloway, and the NoInfo treatments at Tilburg University. At both locations, subjects were (primarily undergraduate) students from a large variety of fields. In the Info treatments experimental points were converted into Pounds Sterling at a rate of 150 points $=£ 1$ and in the NoInfo treatments into Euros at a rate of 100 points $=$ EUR 1 , reflecting roughly the official exchange rate at the time of the experiments. Participants received no show-up fee in addition. Before the first round was started subjects were asked to answer control questions to ensure that everybody had an understanding of how the market works. All sessions were computerized, using z-Tree (Fischbacher, 2007). Sessions took about 90 minutes and average earnings were about EUR 18.

\section{Experimental Results}

In the following discussion of the experimental results, we will study the effects of a price ceiling on various measures, namely the number of collusive prices chosen, the number of colluding firm pairs, the average prices, and the degree of collusiveness. The focal-point hypothesis predicts that in the presence of a price ceiling the firms in a market more frequently manage to coordinate than without a ceiling and specifically that the price they coordinate on will equal the ceiling. To address this hypothesis, we first consider the distribution of observed prices with a focus on the share of prices at the ceiling or above (if permitted), and then the collusiveness in individual markets.

Figures 2 and 3 show for the treatments with and without demand information, respectively, the distribution of individual price choices across all markets and periods, conditional on a ceiling being in place or not. As Figures 2 and 3 show, while prices exactly equal to 28 are more frequent with a ceiling in place, prices larger than or equal to 28 are more frequent without a price ceiling both with and without demand information. Specifically, with demand information, in YesNo, $8.8 \%$ of price choices are equal to 28 in the first phase with a ceiling, but $28.1 \%$ of price choices are $\geq 28$ in the second phase without a ceiling (with $16.9 \%$ at $p=29$ and $2 \%$ at $p=48$ ). In NoYes, $19.7 \%$ of price choices are equal to 28 in the second phase with a ceiling and $17.3 \%$ of price choices are $\geq 28$ in the first phase without a ceiling (with $5.8 \%$ at $p=29$ and $2 \%$ at $p=48$ ). Without demand information, in YesNo, $4.2 \%$ of price choices are equal to 28 in the first phase with a ceiling, but $23.2 \%$ of price choices are $\geq 28$ in the second phase without a ceiling (with $10 \%$ at $p=29$ ). In NoYes, $3.7 \%$ of price choices are equal to 28 in the second phase with a ceiling and $6.2 \%$ of choices satisfy $p \geq 28$ in the first phase without a ceiling (with $0.4 \%$ at $p=29$ ). Overall, these results 


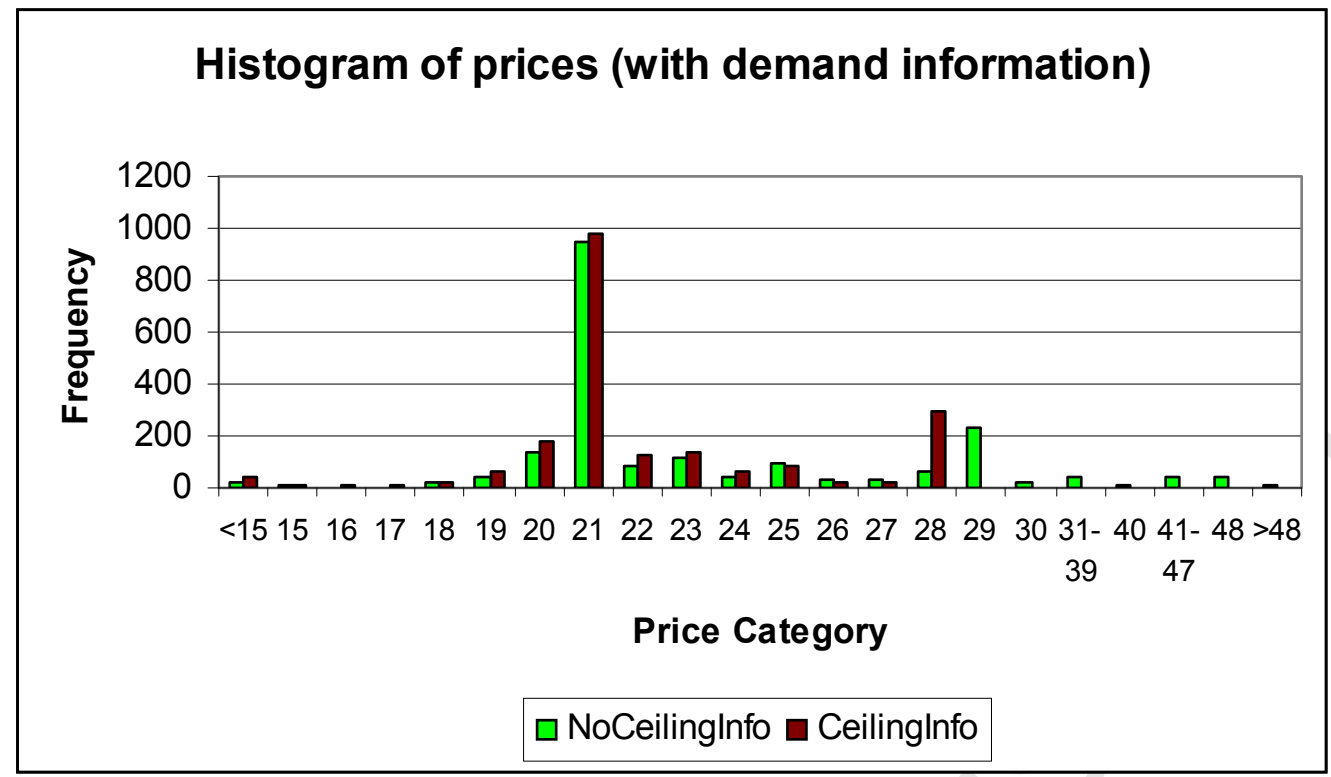

Figure 2: Histogram of price choices for the treatments with demand information.

Note: Extreme categories with few observations are aggregated.

suggest that the concentration at 28 with a ceiling rather results from the ceiling being binding than from serving as focal point. Put differently, the ceiling supresses prices that would otherwise have been higher rather than pulling up prices that would otherwise have been lower.

More generally, prices above the Nash equilibrium occur substantially more frequently without a price ceiling than with a price ceiling both with and without demand information. Furthermore, Nash-equilibrium prices are overwhelmingly the most frequent prices and occur even slightly more frequently with a price ceiling in place than without, both with and without demand information (with demand information: YesNo, with ceiling 51.3\%, without ceiling 53.9\%, NoYes, with ceiling $44.6 \%$, without ceiling $38.9 \%$; without demand information: YesNo, with ceiling 32.4\%, without ceiling $45.5 \%$, NoYes, with ceiling $74.9 \%$, without ceiling $42.7 \%$ ).

Non-parametric tests support these observations. Whenever there are significant differences in the frequency of high prices (that is, prices larger than or equal to 28), both within and across treatments they indicate more high prices without a ceiling. ${ }^{8}$ The frequency of Nash-equilibrium

\footnotetext{
${ }^{8}$ Specifically, Mann-Whitney tests using the number of high price choices in a pair as independent observation, show the following significant effects. With demand information, prices $\geq 28$ are more frequent in periods 1-30 of NoYes than YesNo $(p=0.2 \%)$ but they are more frequent in periods 31-60 of YesNo than NoYes $(p=6.7 \%)$, where the effects in both cases are not significant anymore if we restrict the analysis to the second 15 periods of the phase.
} 


\section{Histogram of prices (without demand information)}

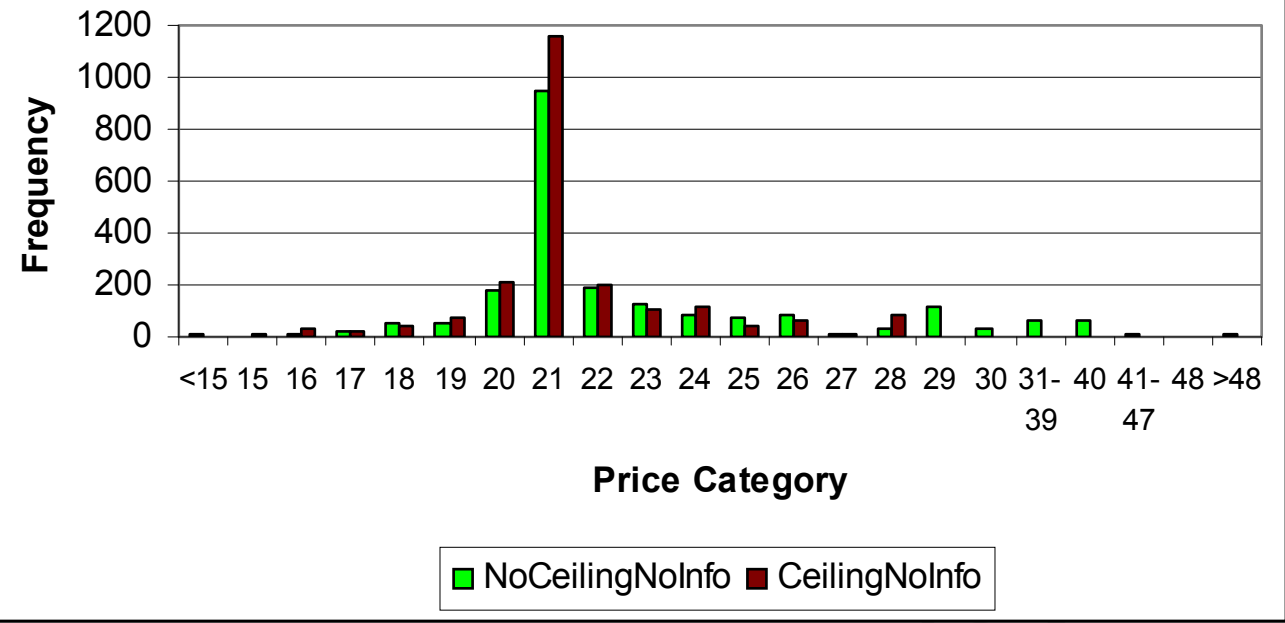

Figure 3: Histogram of price choices for the treatments without demand information.

Note: Extreme categories with few observations are aggregated.

prices increases within treatments for all treatments, ${ }^{9}$ whereas across treatments the only significant difference supports more Nash-equilibrium prices with a ceiling. ${ }^{10}$ We summarize the main result on the price distribution as:

Observation 1 Whenever price ceilings lead to a significant difference in the number of high prices

Without demand information, prices $\geq 28$ are more frequent in NoYes than in YesNo only when restricting attention to periods $1-15(p=4.7 \%)$ but again they are more frequent in periods $31-60$ of YesNo than NoYes $(p=0.1 \%)$, where the effect again loses significance for the last 15 periods. According to Wilcoxon signed-rank tests, comparing early with late periods in the same pair, we find the following significant differences. With demand information, in YesNo high prices become more frequent from periods 1-30 to periods 31-60 $(p<0.1 \%)$ and this effect is significant even if we focus on the last 15 periods in each phase $(p=4.5 \%)$. Without demand information, in YesNo high prices also become more frequent in the second phase $(p=0.6 \%)$, but that effect is not significant if we focus only on the last 15 periods in each phase. In contrast, in NoYes (without demand information) high prices are less frequent in periods 31-60 than 1-30 ( $p=1.4 \%)$, with no significant effect if we compare periods $16-30$ with 46-60.

${ }^{9}$ The increase is significant with demand info in NoYes if we restrict the analysis to periods 1-15 and 31-45 ( $p=3.3 \%)$, without demand info in YesNo from periods 1-30 to 31-60 ( $p=7.4 \%)$ and for 1-15 compared to 31-45 $(p=2.3 \%)$ and in NoYes, from 1-30 to 31-60 $(p<0.1 \%)$ and even for the last 15 periods in each phase $(p=0.3 \%)$.

${ }^{10}$ Without demand information, in periods 31-60 Nash-equilibrium prices occur more frequently in NoYes than in YesNo $(p=0.7 \%)$ with no significant difference in the last 15 periods. 
( $\geq 28)$, they are less frequent with a ceiling in place.

The presence of a price ceiling thus does not lead to a higher frequency of collusive price choices. The focal point hypothesis more specifically predicts that firms will find it easier to coordinate on choosing prices at the price ceiling than to coordinate on any collusive price in the absence of a ceiling. In addition, the presence of a price ceiling restricts the strategy space and this can make coordination easier without coordination necessarily being at the price ceiling itself. We thus consider next the cases where both firms charge the same price and then take a look at individual markets where both firms repeatedly set the same price.

On an aggregate level, simply considering how often both firms in a market charge the same price, there is at best weak evidence in support of the focal-point story. With demand information, in NoYes in $15.5 \%$ of cases both firms charge $p=28$ in the second phase, when the ceiling is in place, whereas only $1 \%$ of price pairs are at $p=29$ in the first phase (and $0.4 \%$ at $p=48$ ). While this is supporting the focal-point hypothesis, in YesNo the pattern is reversed. In the first phase, $5.9 \%$ of price pairs are at the ceiling (all coming from one pair that colludes throughout), whereas $12 \%$ are at $p=29$ in the second phase. This suggests that overall the price ceiling is slightly more successful as a focal point than the kink in the demand curve. We would then expect there to be a stronger effect of the price ceiling in the treatments without demand information where in the part without the ceiling in place no focal point is available. This, however, is not the case. In NoYes, in the second phase no pair ever charges jointly more than $p=23$, and none charges above $p=25$ in the first phase. In YesNo, a negligable share $(0.6 \%)$ of price pairs is at the ceiling in the first phase, while $5.6 \%$ are at $p=26$ and $5.4 \%$ at $p=24$. In the second phase, $2.2 \%, 4.8 \%, 8.3 \%$ and $4.6 \%$ are at $p=24,26,29$, and 40 , respectively. Thus, without demand information, in the first phase coordination seems easier with a price ceiling than without, but this does not occur at the ceiling and hence would support an effect of reducing the strategy space rather than of a focal point.

We now turn to individual markets. In Appendix B in the supplementary material, we present a detailed discussion and a table with the pairs that manage to coordinate on a supracompetitive price for several subsequent periods in at least one phase of the experiment. The main observation is that if pairs of sellers manage to collude, they typically do so in the second half of the experiment. The presence of a price ceiling does not have any effect on the likelihood of achieving collusion. Of the 12 pairs (out of 70) who collude in the second phase, only 5 face a price ceiling, while 7 do not (where one each do not coordinate on a Pareto-improving price). Among the five pairs who collude in the first phase (all of which also cooperate in the second phase), four 


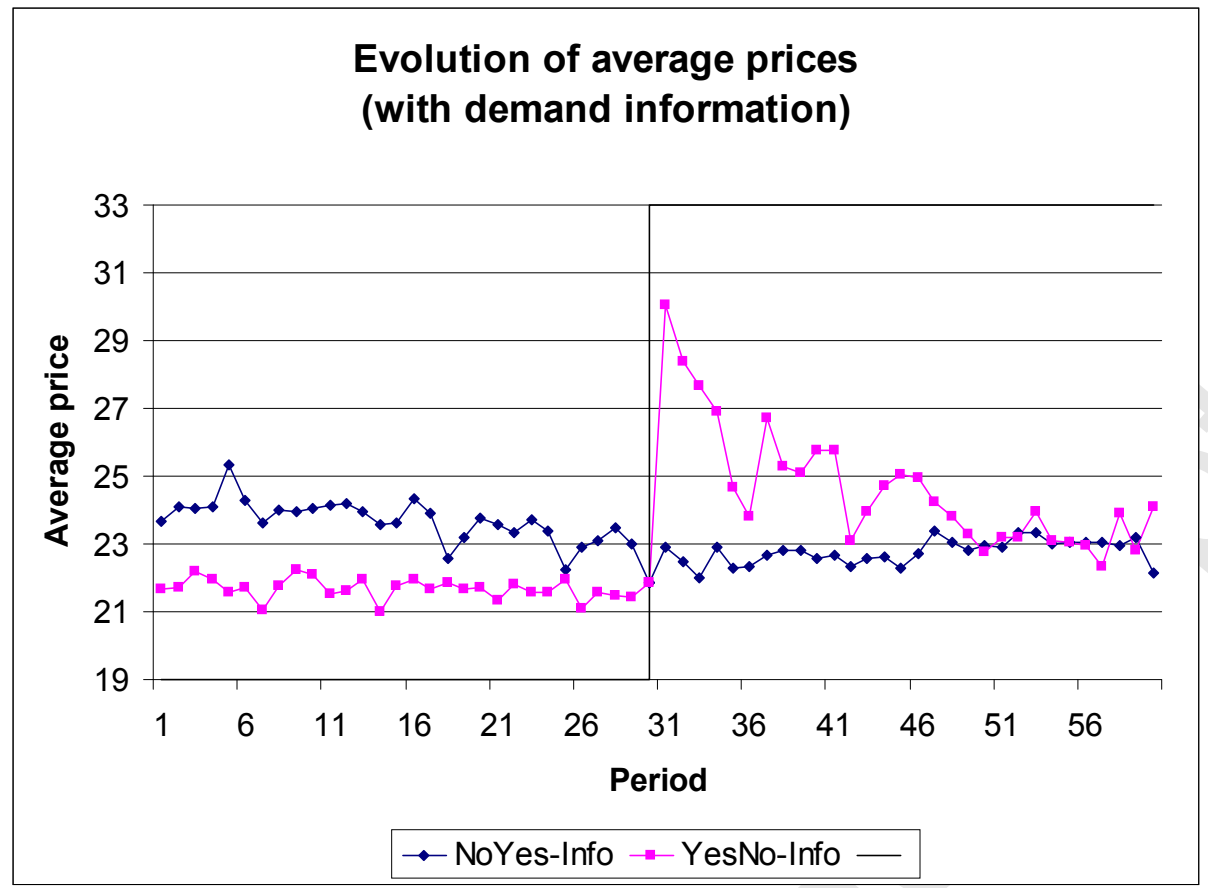

Figure 4: Development of average prices across time in the treatments with demand information. Note: After Period 30 the price ceiling was removed in treatment YesNo and introduced in treatment NoYes.

face a price ceiling, but only one of them actually colludes at the ceiling. This suggests that the price ceiling in the first phase enables coordination by restricting the strategy space rather than by providing a focal point. Remarkably, in the treatments without demand information where the focal-point effect should be particularly strong, not a single pair colludes at the price ceiling, neither in the first nor the second phase. Overall, studying individual markets, we see little evidence that a price ceiling facilitates collusion and hardly at the ceiling.

From a competition-policy perspective, one might be concerned not necessarily with collusion per se, but rather with the resulting prices. If attempts at collusion, even though unsuccessful, still yield higher prices on average, this is clearly not desirable. Hence, we now take a broader look at the overall effects of the presence of the price ceiling, starting with the development of average prices by treatment.

Figure 4 shows average prices across periods for the treatments with demand information and Figure 5 for the treatments without demand information. These are averages of the posted prices, not weighted by quantity sold. Inspecting Figures 4 and 5, we make a number of observations. First, the treatments that start with a price ceiling (YesNo) show an almost identical pattern with 


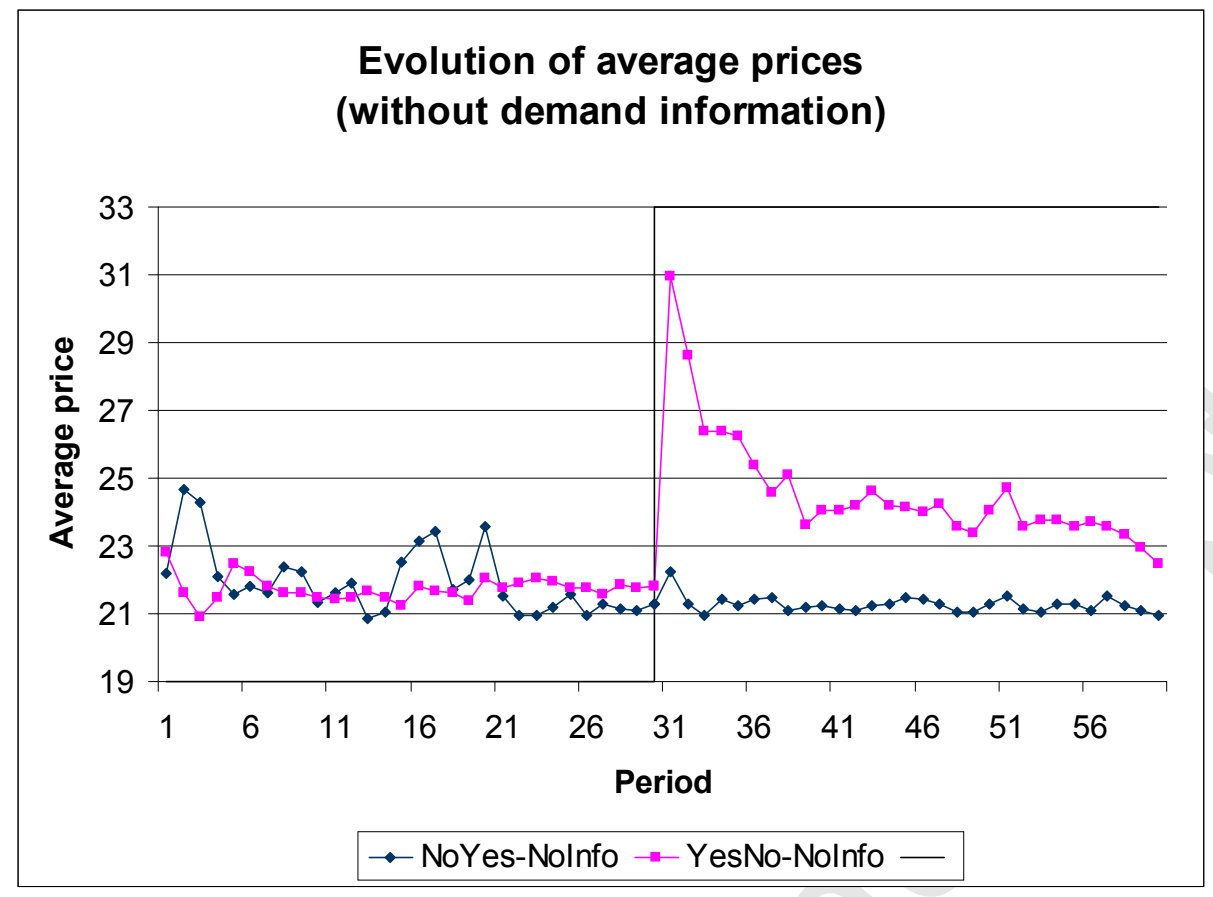

Figure 5: Development of average prices across time in the treatments without demand information. Note: After Period 30 the price ceiling was removed in treatment YesNo and introduced in treatment NoYes.

and without demand information. Specifically, average prices are only slightly above the Nashequilibrium price 21 and do not vary much within the first 30 periods with a price ceiling in place. Abolishing the price ceiling leads to an "explosion" of average prices above the former ceiling (28), but they then quickly decline and tend towards about 23. Such price explosions have also been observed in the previous experiments on price ceilings. ${ }^{11}$ In order to eliminate any biases based on these temporary effects, we will below also look separately at the latter half of each phase. Second, for both information conditions in the treatments that start without a price ceiling (NoYes) average prices decline slightly over the first 30 periods and the introduction of the price ceiling has no notable effect, with prices being nearly constant in the last 30 periods. However, for the NoYes

\footnotetext{
${ }^{11}$ This upward jump in average prices can have a number of explanations. First, the abolishing of the price ceiling dramatically increases the strategy space and thus random behavior would lead to much higher average prices. This does not, however, explain why average prices are higher here than in the first few periods of the first phase in treatment NoYes. Second, abolishing the price ceiling might be interpreted as a signal that successful prices are above the former ceiling. Starting a new search for high-profit prices would thus lead to high average prices. Third, some subjects might choose excessively high prices as a signal to their competitor that they should aim for higher prices than those obtained so far.
} 
treatments prices are consistently about 2 units higher with demand information than without. This appears to be driven by more widespread attempts (in both phases) to collude in the NoYes markets with information than without information (see above). ${ }^{12}$ Third, addressing our main question, across-treatment comparisons show that if a price ceiling has an effect, it lowers rather than increases average prices. Specifically, with demand information, prices are higher without a ceiling except for about the last 15 periods, where they are essentially equal. Without demand information, there is essentially no difference in the first 30 periods, while in the last 30 periods, prices are consistently lower with a price ceiling.

Corresponding aggregate data and the results of statistical tests are presented in the upper half of Table 5. The collusion index data presented in the lower part of the table will be discussed below. We focus on the price data for the moment. The table contains average prices across pairs and blocks of periods for the various treatments. From left to right, the first column shows averages across the whole first phase (periods 1-30), the second column across the whole second phase (periods 31-60), the next two columns the averages across the first halves of the respective phases (periods 1-15 and 31-45, respectively) and the last two columns the averages across the second halves (periods 16-30 and 46-60, respectively).

We note first, consistent with our observations above on the distribution of price choices, that average prices in any treatment and any phase (or part thereof) are well below the price ceiling of 28 and in the second half of each phase, they are always closer to the Nash-equilibrium price of 21 than to the price ceiling.

The " $<$ ", ">", and " $\approx$ " signs summarize the results of statistical tests, with " $\approx$ " indicating no significant difference at the 10\%-level. The superscripts indicate the level of significance. Our focus is on the vertical comparisons, testing for differences across treatments in the same block of periods (i.e. testing for difference between the distributions underlying the number right above and the one right below the sign). We apply non-parametric Mann-Whitney tests here, with the average prices within pairs across the respective periods as independent observations.

Looking first at the treatments with demand information and the first two columns, we see that prices are significantly higher in NoYes than in YesNo in the first phase, but that this is

\footnotetext{
${ }^{12}$ This could be simply the result of subjects in this treatment being more eager to cooperate. Alternatively, given demand information, in the absence of the ceiling, attempting to collude at $p=29$ or $p=48$ are attractive choices (and account for $6 \%$ and $2 \%$ of price choices), which drives up average prices. These attempts to collude could then translate to attempts to collude at the ceiling in the second phase, leading to higher prices throughout.
} 


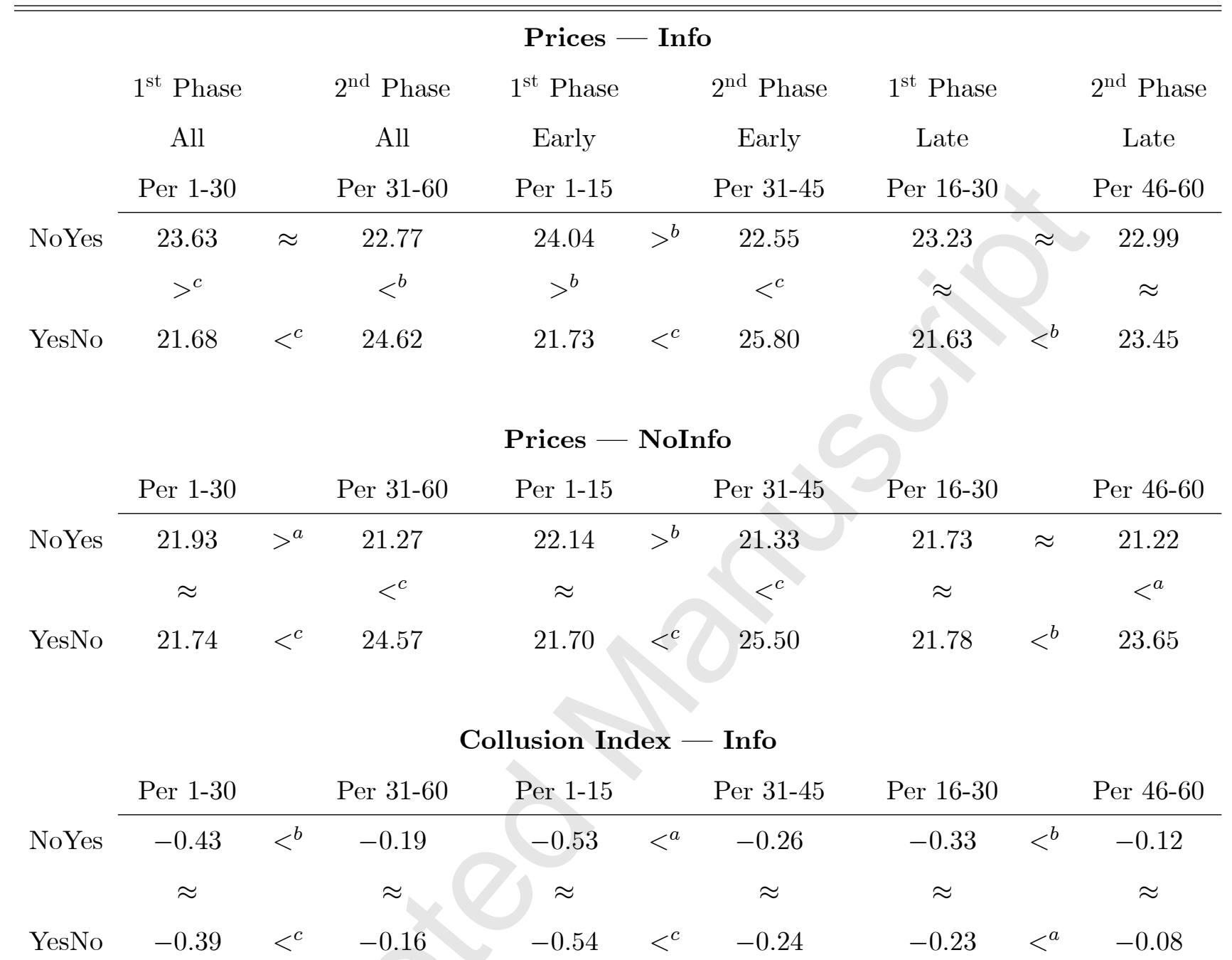

\section{Collusion Index - NoInfo}

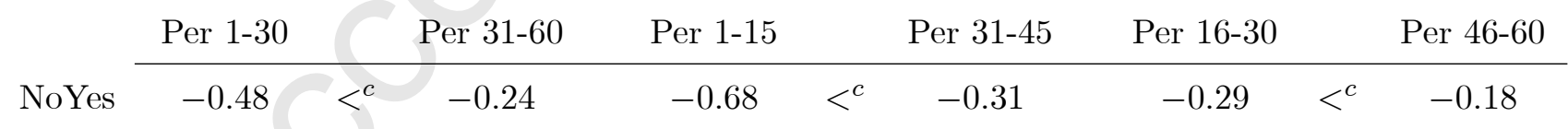

\begin{tabular}{|c|c|c|c|c|c|c|c|c|c|}
\hline & & & $\approx$ & $\approx$ & & $\approx$ & $\approx$ & & $\approx$ \\
\hline YesNo & -0.51 & $<^{c}$ & -0.17 & -0.72 & $<^{c}$ & -0.30 & -0.30 & $<^{b}$ & -0.04 \\
\hline
\end{tabular}

Note: Comparisons within treatments (horizontal) are based on Wilcoxon signed-rank tests, comparions across treatments (vertical) on Mann-Whitney tests. Significance: $a: p<0.1, b: p<0.05, c: p<0.01$.

Table 5: Summary statistics, Prices (upper half) and Collusion indices (lower half) 
reversed in the second phase. This implies that in both phases, the average prices are higher in the treatment without a price ceiling. Considering the different halves of each phases, we see that the differences are primarily driven by the early periods of each phase, where we get the same relation, whereas there are no significant differences in the late periods.

The results for the treatments without demand information differ somewhat. The difference in the first phase is not significant (note that prices here are actually very close to the Nash-equilibrium price 21 in both treatments). The difference in the second phase is even more pronounced than in the Info treatments and is even also (weakly) significant if we consider only the late periods in each phase. This is consistent with the observations made above in Figures 4 and 5 . Prices in the NoYes treatments are consistently higher with demand information than without, while there is no difference between the two YesNo treatments. The crucial result, however, is the same with and without demand information: whenever there is a significant difference, it is in the direction of higher prices without a ceiling.

One reason why we typically find lower prices with a ceiling than without is that the ceiling would occasionally be binding, at least in early periods. We can control for this by replacing all prices $>28$ when no ceiling is in place with the ceiling price 28 , hence implying the price we would obtain if a ceiling had been in place and had only affected high prices by becoming binding, but not affected lower prices. Even these censored prices are higher than prices when a ceiling is in place, both with and without demand information (22.91 vs. 22.23 and 22.41 vs. 21.51 , respectively).

We also compare prices within treatments across the phases (the horizontal comparisons in Table 5). Since data are matched, we use Wilcoxon signed-rank tests for these comparisons, using the average per group as independent observation. Again whenever there is a significant difference it is in the direction of higher prices without a price ceiling. We get the same results with demand information as without, except for one case (in NoYes the overall comparison is weakly significant in NoInfo, but not in Info). Imposing a price ceiling (in NoYes) leads to lower prices in early periods, but the effect virtually disappears towards later periods. In contrast, lifting a price ceiling (in YesNo) leads to higher prices. It is particularly noteworthy that in YesNo, the higher prices in the second phase are not exclusively driven by the price explosion after the abolition of the ceiling. Even restricting the analysis to the late periods of each phase, the prices are significantly higher in the second phase at the $5 \%$ level, both with and without demand information.

We do not provide statistical tests for the comparison of prices with and without demand information. We are not interested in the question whether demand information leads to higher 
or lower prices. ${ }^{13}$ As argued above, the rationale for conducting treatments with and without demand information is to provide a test of the effect of price ceilings in two different settings. More precisely, by removing common knowledge on kinks in the demand curve that could serve as alternative focal points, we give the hypothesis that price ceilings could lead to more collusion a better shot in NoInfo. The observation that prices in NoYes are significantly higher than in YesNo in the first phase with demand information but not without is consistent with the expectation that in the absence of a ceiling, it is easier to collude with demand information than without. We note, however, that prices in NoYes are higher in Info than in NoInfo even in the second phase, where a ceiling was in place and collusion at the kink not possible. There are two possible explanations. First, the demand information could have helped subjects to realize that the price ceiling is the profit maximizing price when it is in place. Second, the subject pool may have differed in their tendency towards collusion. In any case, we reiterate that the comparisons between information conditions is not our concern and that the crucial result is that under both conditions, we find that the presence of a price ceiling never leads to higher prices but frequently to significantly lower ones. We summarize the results on average prices as:

Observation 2 Comparing across treatments, price ceilings lead in no comparison to higher prices but often to significantly lower prices.

Observation 3 Comparing across phases within treatments, imposing a price ceiling leads to significantly lower prices in the early periods. Lifting a price ceiling leads to significantly higher prices both in the early and late periods of the second phase.

So far we addressed only prices. These do not, however, completely reflect the degree of collusiveness in the market. Specifically, because of increasing marginal costs, firms are jointly better off if they set equal prices and as discussed above, equal prices above equilibrium occur somewhat more frequently with a price ceiling. ${ }^{14}$ To measure the impact on firms' profits, we define collusion indices for the respective phases as follows:

$$
I=\frac{\pi^{\text {actual }}-\pi^{\text {Nash }}}{\pi^{\text {Cartel }}-\pi^{\text {Nash }}} \quad \text { (when no ceiling is in place) }
$$

\footnotetext{
${ }^{13}$ Furthermore, the treatments were run with different subject pools so that we would not be able to conclude with certainty that any differences are indeed driven by the information condition.

${ }^{14}$ Furthermore, once one firm sells nothing, raising its price even further will not affect profits or welfare.
} 
or

$$
I=\frac{\pi^{\text {actual }}-\pi^{\text {Nash }}}{\pi^{\text {Ceiling }}-\pi^{\text {Nash }}} \quad \text { (when a ceiling is in place) }
$$

where $\pi^{\text {actual }}$ is the actual achieved joint profit, $\pi^{\text {Nash }}$ is the joint Nash-equilibrium profit, $\pi^{\text {Ceiling }}$ is the joint profit if both firms set a price equal to the ceiling and $\pi^{\text {Cartel }}$ is the maximum possible joint profit if there is no ceiling in place. This means we define the collusion index such that it equals 1 at the maximal joint profit. It is 0 if both sellers choose Nash-equilibrium prices. With a price ceiling the maximum profit is achieved if both firms choose the price at the ceiling, without a price ceiling it is obtained if both sellers choose $P=48$ (see Section 2.2). The average collusion indices for the different treatments and phases are in the lower half of Table 5, which is structured in the same way as the upper half for the average prices.

The first crucial observation is that all aggregate collusion indices are negative, that is average profits are below Nash-equilibrium profits in all parts in all treatments. ${ }^{15}$ Next, we see that in each comparison between phases the collusion index is significantly higher in the second phase. This holds for the complete phases, as well as for the early and late periods within each phase. This means profits move towards Nash profits over time. This happens primarily because firms converge towards setting equal prices (which is then frequently the Nash price). Finally, for no phase or part of a phase does the collusion index differ significantly between treatments. ${ }^{16} \mathrm{We}$ again do not compare between the treatments with and without demand information but note that the pattern is very similar with and without demand information. Hence, the presence of a price ceiling never affects the degree of collusiveness significantly. ${ }^{17}$ We summarize these results as:

Observation 4 In all treatments the degree of collusiveness increases over time, but stays below Nash-equilibrium levels, i.e. joint profits approach the Nash-equilibrium level from below.

\footnotetext{
${ }^{15}$ Remember that the Nash equilibrium coincides with the upper end of the competitive price range. Joint profits below the Nash-equilibrium profits do not in general imply that firms set prices below the equilibrium, but rather that they choose different prices. This yields lower profits because of increasing marginal costs, which lead to inefficient splits of demand for unequal prices.

${ }^{16}$ If we consider market profits instead of the collusion index, we find that these are about $2 \%$ higher with a ceiling than without. This holds both with and without demand information. The marginally higher profits with a ceiling are not driven by firms setting higher prices, but by more frequently setting equal prices, which is easier if the strategy space is smaller. Interestingly, in both conditions, in the last 15 periods, profits are slightly higher without a ceiling.

${ }^{17}$ We also ran regressions taking into account the dependence of data within a pair. Considering the impact of a dummy for the presence of a price ceiling on average prices and the collusion index, these results are fully consistent with the non-parametric tests, with minor differences in significance levels.
} 
Observation 5 Comparing across treatments, the presence of a ceiling never has a significant impact on the degree of collusiveness.

Finally, from the perspective of the competition authority, the ultimate goal is not competitiveness per se but welfare. We thus also compared welfare (as the sum of the, hypothetical, consumer surplus and producer surplus) across phases and treatments. In line with the results above, we cannot detect a detrimental effect of price ceilings. Whenever there are significant differences across or within treatments, welfare is higher with a price ceiling than without.

\section{Conclusions}

In this paper we report on a new attempt to induce a collusive focal-point effect of price ceilings in laboratory markets. Our design features elements that we considered favorable to induce such an effect: (a) posted-offer markets; (b) relatively larger incentives to collude at the ceiling compared to earlier studies; (c) fixed pairs of two sellers; (d) simulated demand; (e) cost asymmetries among sellers; and in half of our treatments (f) very limited information about demand.

Yet, contrary to our expectations, in none of our treatments do price ceilings lead to more collusion. This is true with respect to several measures: the number of high prices chosen; the number of colluding pairs; average prices; the degree of collusiveness (as measured by a standard collusion index); and welfare. More precisely, whenever we do observe significant differences with respect to any of these measures, these differences point in the direction of less collusion when a price ceiling is in place. Hence, this new search for a collusive focal-point effect in laboratory markets was not successful either. Since our design was more favorable for such an effect to occur than the designs in previous studies, our results strengthen the finding that establishing a collusive effect of price ceilings is difficult in the laboratory. As a result, they further question the empirical validity of the focal-point hypothesis.

This is reminiscent of Isaac and Smith's (1985) elusive search for predatory pricing in the laboratory. ${ }^{18}$ In light of the evidence for collusive effects of price ceilings in various field markets cited in the introduction this is puzzling. More research is needed to pin down the exact circumstances that enable a "behavioral existence proof" (Goeree, Gomez, and Holt, 2008) for a

\footnotetext{
${ }^{18}$ Harrison (1988), Jung, Kagel, and Levin (1994), and Capra et al. (2000) later found evidence of predatory pricing in the laboratory.
} 
collusive focal-point effect of price ceilings. ${ }^{19,} 20$

There are two distinct possible explanations for the apparent difficulty to induce a focalpoint effect of price ceilings in the laboratory in spite of empirical evidence in line with the focalpoint hypothesis in the field. The first is that there is something fundamentally different about market structure or market participants between the laboratory and the field and that all experiments failed to reflect crucial aspects that enable the focal-point effect in the field. As we argued in the introduction, we believe this to be less relevant for a test of the focal-point hypothesis than it might be for market experiments in general. However, one such issue could be that firms in the field may have a long history of unsuccessful attempts at collusion and hence can appreciate the presence of a coordinating device more. Our results that show successful collusion at the price ceiling more often in the second phase of the experiment than in the first (and following unsuccessful attempts at coordinating on high prices) are in line with such a view. On the other hand, in the experiment this might just be a pure re-start effect, as we see collusion without a ceiling also more frequently in the second phase. Furthermore, one would expect that firms that have long been attempting to collude have found other ways of achieving this than relying on a simple focal point.

The second possible explanation for the lack of evidence in favour of the focal-point hypothesis in the laboratory, in spite of its apparent support in the field is that the reason for the field phenomena is not the focal-point effect either. According to this interpretation, also in the field there is not simply a selection problem for tacit collusion that is solved by the price ceiling but the field results are driven by other factors. These might include explicit collusion (which might either be triggered by the introduction of the price ceiling or might be easier to keep up in its presence) or other reasons that the empirical studies failed to control for. We consider the main contribution of laboratory experiments failing to replicate certain phenomena from the field precisely to inspire us to think more about alternative explanations for the field phenomena themselves.

As one such potential additional explanation for collusive effects of price ceilings in the field, a price ceiling might well be interpreted (and indeed quite possibly correctly) as a signal that up to that price firms would not be investigated for collusion. After regulating a price there seems little

\footnotetext{
${ }^{19}$ Among possible alternatives for further research are to check the effect of allowing sellers to communicate, having groups instead of individuals act in the role of sellers and of using experienced subjects.

${ }^{20}$ We note that achieving collusion in the laboratory is not in general impossible. Among many examples, Li and Plott (2009) as well as Brown, Plott, and Sullivan (2009) show that a so-called "collusion incubator" environment quickly and reliably generates tacit collusion in a simultaneous ascending-price auction.
} 
reason to investigate if prices are actually clustered at the ceiling, because a ceiling would typically be set at a level where the authorities would expect it to be potentially binding. Collusion, be it tacit or explicit, is therefore far less risky than it would be at a comparable price level if no ceiling was in place. Thus, collusion at a price ceiling would not be facilitated because it reduces the coordination problem but because it reduces the (perceived as well as possibly actual) risk for firms of being accused of collusion. This interpretation is also consistent with observed patterns in the field. For example, if the price ceiling is very high, firms can expect that the competition authority would not expect it to be binding so that it would be likely to investigate relatively high prices. This in turn discourages collusion and could hence explain why sometimes lower prices are observed with higher ceilings. More generally, any observation that is consistent with collusion at the price ceiling is consistent with this signalling of impunity explanation as well as with the focal-point hypothesis because both explanations suggest that pricing at the ceiling might be collusive, but the data can typically not shed light on why collusion might happen.

In contrast to the focal-point hypothesis, we would not expect any such signalling of impunity effect of price ceilings in the laboratory, simply because collusion is not discouraged or in any way punished in the experimental markets. Consequently, the signalling of impunity hypothesis is better able than the focal-point hypothesis to explain simultaneously why price ceilings appear to enable collusion in the field but not in the laboratory. ${ }^{21}$ Identifying which of these two hypotheses (or conceivable alternative) underlies apparent collusion appears to be very difficult with field data.

\footnotetext{
${ }^{21}$ At face value, the signalling of impunity hypothesis would rather predict that we see collusion in the laboratory both with and without a ceiling because it is never punished there. This suggests that in the field, collusion must generally be easier than in the laboratory, for example due to abilities to communicate. This is then discouraged by possible punishment, which is in turn countered by the price ceiling. We also note, however, that experimental designs for tests of the focal-point hypothesis, including ours, have typically been chosen to make collusion not too easy without a price ceiling, so that we can potentially observe a collusive effect of price ceilings. To test for the signalling of impunity hypothesis in the laboratory requires an altogether different design, namely were collusion is easy, but discouraged through possible punishment, with a price ceiling serving as a signal for the prices which may or may not imply punishment.
} 


\section{References}

Borck, R., Engelmann, D., Müller, W., Normann, H.-T., 2002. Tax liability side equivalence in an experimental posted offer market. Southern Economic Journal 68, 672-682.

Brown, A.L, Plott, C.R., Sullivan, H.J., 2009. Collusion facilitating and collusion breaking power of simultaneous ascending price and descending price auctions. Economic Inquiry 47, 395-424.

Capra, M., Goeree, J., Gomez, R., Holt, C., 2000. Predation, asymmetric information, and strategic behavior in the classroom. International Journal of Industrial Organization 18, $205-225$.

Coursey, D., Smith, V.L., 1983. Price controls in a posted offer market. American Economic Review 73, 218-21.

Davis, D. and Holt, C., 1993. Experimental Economics. Princeton University Press, Princeton, NJ.

DeYoung, R. and Phillips, R.J., 2006. Strategic pricing of payday loans: evidence from Colorado, 2000-2005. Indiana State University, Networks Financial Institute, Working Paper No. 2006WP-05.

Engelmann, D., Normann, H.-T., 2009. Price ceilings as focal points? an experimental test. In: Hinloopen, J., Normann, H.-T., (Eds.). Experiments for Antitrust Policies. Cambridge University Press, Cambridge, UK. pp. 61-80.

Eriksson, R., 2004. Testing for price leadership and for reputation goods effects: Swedish dental services. Swedish Institute for Social Research (SOFI), Stockholm University, Working Paper $5 / 2004$.

Fischbacher, U., 2007. Z-Tree, Zurich toolbox for readymade economic experiments. Experimental Economics 10, 171-178.

Goeree, J., Gomez, R., Holt, C., 2008. Predatory pricing: rare like a unicorn? In: Plott, C., Smith, V. (Eds.). Handbook of Experimental Economics Results. North-Holland, Amsterdam. pp. 178-184.

Harrison, G.W., 1988. Predatory pricing in a multiple market experiment. A Note. Journal of Economic Behavior and Organization 9, 405-417. 
Huck, S., Normann, H.-T., Oechssler, J., 2004. Two are few and four are many: number effects in experimental oligopoly. Journal of Economic Behavior and Organization 53, 435-446 .

Isaac, R.M., Plott, C.R., 1981. Price controls and the behavior of auction markets: an experimental examination. American Economic Review 71, 448-459.

Isaac, R.M., Smith, V.L., 1985. In search of predatory pricing. Journal of Political Economy 93, $320-345$.

Jung, Y.J., Kagel, J.H., Levin, D., 1994. On the existence of predatory pricing: an experimental study of reputation and entry deterrence in the chain-store game. RAND Journal of Economics 25, 72-93.

Knittel, R.K., Stango, V., 2003. Price ceilings as focal points for tacit collusion: evidence from credit cards. American Economic Review 93, 1703-1729.

Li, J., Plott, C.R., 2009. Tacit collusion in auctions and conditions for its facilitation and prevention: equilibrium selection in laboratory experimental markets. Economic Inquiry 47, $425-448$.

Ma, T.-C., 2007. Import quotas, price ceilings, and pricing behavior in Taiwan's flour industry. Agribusiness 23, 1-15.

Normann, H.-T., Wallace, B., 2006. The impact of the termination rule on cooperation in a prisoner's dilemma experiment. Working Paper, Goethe University Frankfurt.

Schelling, T., 1960. The Strategy of Conflict. Harvard University Press, Cambridge, MA.

Scherer, F.M., Ross, D., 1990. Industrial Market Structure and Economic Performance, 3rd ed., Boston: Houghton Mifflin.

Sheahan, J., 1961. Problems and possibilities of industrial price control: postwar French experience. American Economic Review 51, 345-359.

Smith, V., Williams, A., 1981. On non-binding price controls in a competitive market. American Economic Review 71, 467-471.

Tirole, J., 1988. The Theory of Industrial Organization. MIT Press, Cambridge, MA. 
Highlights of the paper "Collusion through price ceilings? In search of a focal-point effect"

- We resume the search for a focal-point effect of price ceilings in lab markets.

- Our design aims at maximizing the likelihood of a collusive focal-point effect.

- Nevertheless, our results again fail to support the focal-point hypothesis.

- Collusion is as unlikely in markets with as in markets without a price ceiling.

- This is in contrast to field studies on anti-competitive effects of price ceilings. 